\title{
Anaesthesia for Ophthalmic Procedures in a Teaching Hospital
}

\author{
CO Imarengiaye, MBBS, FWACS, FMCA, FICS; SA Adamu, MBBS, FMCA; T Isesele, MBBS, DA; \\ S O Tudjegbe, MBBS, FMCA \\ Department of Anaesthesiology, University of Benin, Benin City, Nigeria
}

\section{SUMMARY}

Objectives: To study the pattern of anaesthesia for ophthalmic procedures in order to improve the scheduling of cases in the ophthalmic operating room.

Methods: The surgical register of the operating room from August 01, 1999 to July 31, 2004 was examined, to document the types of procedure, timing of surgery (elective or emergency), methods of anaesthesia, and involvement of anaesthesia personnel.

Results: A total of 970 patients (506 males, 464 females) had ophthalmic surgery in the five-year period under review. General anaesthesia was employed for 119 (12.3\%) patients and regional anaesthesia for 851 (87.7\%). 400 patients had their procedures on ambulatory basis $(L A=397, G A=3)$. Local blocks were the favoured technique for both the outpatient and inpatient settings. Cataract extraction, repair of corneal/scleral/conjunctival/lid lacerations, excision biopsy, trabeculectomy and evisceration were the leading indications. General anaesthesia was the more commonly employed anaesthetic technique in younger patients and for emergency ophthalmic procedures. The general anaesthesia was administered by the registrar and senior registrar grades of anaesthetists.

Conclusion: The study shows that the use of general anaesthesia appeared largely restricted to paediatric patients and emergency situations. However, evolving techniques - like sub-tenon block, total intravenous anaesthesia (TIVA), monitored anaesthesia care - should be encouraged.

Key words: ophthalmic anaesthesia, paediatric anaesthesia, regional blocks, outcome

\section{INTRODUCTION}

Ophthalmic anaesthesia is an aspect of patient care in which the surgeon plays a pivotal role. The anaesthetic options are often limited to general anaesthesia and local blocks. Local anaesthetic blocks such as retrobulbar or peribulbar blocks are commonly performed by the ophthalmologist. Topical anaesthesia is emerging as an additional technique in ophthalmic anaesthesia. Indeed, changes in surgical techniques have also influenced the anaesthetic technique. For example, the use of phacoemulsification has been adduced as a reason for the shift from general to local anaesthesia for cataract surgery. ${ }^{1}$

The number of anaesthetic options for ocular procedures has increased over the years. The local anaesthetic options include retrobulbar, peribulbar, sub-tenon, ${ }^{1}$ and topical anaesthesia $^{2}$ with or without sedation. ${ }^{3}$ Similarly, general anaesthesia has evolved to include the use of the laryngeal mask airway (LMA), total intravenous anaesthesia (TIVA), ${ }^{4}$ or a combination of local anaesthesia and general anaesthesia. ${ }^{5}$ These changes notwithstanding, it is often assumed that the ophthalmic surgeon will provide sufficient coverage for the ophthalmic operating room. This thinking has led to occasional non-availability of anaesthetic personnel in the ophthalmic theatre and consequent poor scheduling of operating room time. It is important that the pattern of cases in the ophthalmic theatres and anaesthetic requirement are clearly delineated in this sub-region. This study thus evaluates the patterns and determinants of anaesthesia for ophthalmic procedures in a teaching hospital in Nigeria.

\section{METHOD}

The surgical registry of the ophthalmic theatre was examined to identify the various procedures performed between August 01, 1999 and July 31, 2004 at the University of Benin Teaching Hospital. The register was examined to determine the pattern of surgical procedures performed in the unit. The sociodemographic characteristics of the patients were recorded. For each patient, the surgical procedure, nature of surgery (elective or emergency), the anaesthetic technique, and the level of anaesthetic care provider were recorded. The scheduling of patients for an elective procedure could be on inpatient or outpatient basis. An elective procedure was defined as one scheduled on the daily published operating list of the ophthalmic unit. An outpatient was defined as a

${ }^{*}$ Correspondence: Dr. CO Imarengiaye, Department of Anaesthesiology, University of Benin Teaching Hospital, PMB 1111, Benin City, Nigeria 
procedure where a patient was instructed to attend on the day of surgery and was to be discharged on the same day and so indicated on the published operating list.

The association between the age of the patients, and circumstance of the surgical procedure and the technique of anaesthesia was examined using the Fisher exact test. A probability of $5 \%$ was considered significant.

\section{RESULTS}

A total of 970 (506 men, 464 women) patients had ophthalmic surgery during the period under review. General anaesthesia was employed for $119(12.3 \%)$ patients and local anaesthesia for $851(87.7 \%)$; $570(58.8 \%)$ were inpatients and $400(41.2 \%)$ patients had their procedures on outpatient basis. The various techniques of anaesthesia are shown in table 1. Local blocks were the favoured technique for both the outpatient or inpatient settings $(\mathrm{p}<0.001, \mathrm{OR}=33.8,95 \% \mathrm{CI}=10.7-107.2$, Fisher exact test).

Table 1. Surgical setting and technique of anaesthesia

\begin{tabular}{lcccccc}
\hline Setting & \multicolumn{2}{c}{ Number } & \multicolumn{2}{c}{$\begin{array}{c}\text { Local } \\
\text { anaesthesia }\end{array}$} & \multicolumn{2}{c}{$\begin{array}{c}\text { General } \\
\text { anaesthesia }\end{array}$} \\
& $(\mathrm{n})$ & $\%$ & $(\mathrm{n})$ & $\%$ & $(\mathrm{n})$ & $\%$ \\
\hline $\begin{array}{l}\text { Out- } \\
\text { patient }\end{array}$ & 400 & 41.2 & 397 & 46.7 & 3 & 2.5 \\
$\begin{array}{l}\text { In-patient } \\
\text { Total }\end{array}$ & 570 & 58.8 & 454 & 53.3 & 116 & 97.5 \\
\hline
\end{tabular}

$(\mathrm{p}<0.001, \mathrm{OR}=33.8,95 \% \mathrm{CI}=10.7-107.2)$

Table 2 shows the various ophthalmic surgical procedures performed in the unit within the period. Cataract extraction, repair of lacerations of the cornea/sclera/conjunctiva/lid, excisional biopsy, trabeculectomy and evisceration were the leading indications.

Table 2. Procedures and technique of anaesthesia

\begin{tabular}{lrrrr}
\hline Procedure & \multicolumn{2}{c}{ LA } & \multicolumn{2}{c}{ GA } \\
& (n) & $\%$ & (n) & \multicolumn{1}{c}{$\%$} \\
\hline Cataract & 305 & 35.9 & 30 & 25.2 \\
Trabeculectomy & 31 & 3.6 & 4 & 3.4 \\
Capsulotomy & 4 & 0.5 & 3 & 2.5 \\
Repair of corneal/ scleral/ & & & & \\
$\quad$ conjunctival/lid lacerations & 84 & 9.9 & 19 & 16.0 \\
Excisional biopsy & 49 & 5.8 & 10 & 8.4 \\
Anterior chamber washout & 11 & 1.3 & 7 & 5.9 \\
Enucleation & 7 & 0.8 & 10 & 8.4 \\
Evisceration & 30 & 3.5 & 5 & 4.2 \\
Examination under & & & & \\
$\quad$ anaesthesia & 5 & 0.6 & 18 & 15.1 \\
Removal of stitches & 2 & 0.2 & 5 & 4.2 \\
Squint surgery & 13 & 1.5 & 3 & 2.5 \\
Others & 310 & 36.4 & 5 & 4.2 \\
\hline Total & 851 & 100.0 & 119 & 100.0 \\
\hline
\end{tabular}

General anaesthesia was the more commonly employed anaesthetic technique in the younger age group than local anaesthesia $(\mathrm{p}<0.001, \mathrm{OR}=44.9,95 \% \mathrm{CI}=27.2-74.0$, Fisher's exact test) especially in the first decade of life as shown in table 3. Table 4 shows that general anaesthesia was more likely for emergency ophthalmic procedures than local anaesthesia $(\mathrm{p}<0.0001, \mathrm{OR}=6.7,95 \% \mathrm{CI}=4.1-10.8)$. General anaesthesia was administered by a registrar in 41 cases, a senior registrar in 77 cases and a consultant for one case.

Table 3. Age distribution of patients and technique of anaesthesia

\begin{tabular}{lcccc}
\hline \multirow{2}{*}{ Age } & \multicolumn{2}{c}{ GA } & \multicolumn{2}{c}{ LA } \\
\cline { 2 - 5 } & (n) & $\%$ & $(\mathrm{n})$ & $\%$ \\
\hline $0-9$ & 83 & 69.7 & 13 & 1.5 \\
$10-19$ & 12 & 10.1 & 55 & 6.5 \\
$20-29$ & 3 & 2.5 & 165 & 19.4 \\
$30-39$ & 5 & 4.2 & 124 & 14.6 \\
$40-49$ & 4 & 3.4 & 135 & 15.8 \\
$50-59$ & 5 & 4.2 & 125 & 14.7 \\
$\geq 60$ & 7 & 5.9 & 234 & 27.5 \\
\hline Total & 119 & 100.0 & 851 & 100.0 \\
\hline
\end{tabular}

Table 4. Nature of procedure and types of anaesthesia

\begin{tabular}{lcccc}
\hline $\begin{array}{l}\text { Nature of } \\
\text { surgery }\end{array}$ & \multicolumn{2}{c}{ General anaesthesia } & \multicolumn{2}{c}{ Local anaesthesia } \\
& $(\mathrm{n})$ & $\%$ & $(\mathrm{n})$ & $\%$ \\
\hline Elective & 83 & 69.7 & 799 & 93.9 \\
Emergency & 36 & 30.3 & 52 & 6.1 \\
\hline Total & 119 & 100.0 & 851 & 100.0 \\
\hline$(\mathrm{p}<0.0001, \mathrm{OR}=6.7,95 \% \mathrm{CI}=4.1-10.8)$ & &
\end{tabular}

\section{DISCUSSION}

This study shows that local anaesthetic block was the main method of anaesthesia for ophthalmic procedures whether on in-patient or ambulatory basis. The choice of anaesthesia for ocular procedures is determined by the surgeons' preferences and the setting. ${ }^{6}$ These preferences are further modulated by the availability of skilled anaesthetic personnel, especially in developing countries. Although our centre has a full complement of specialist anaesthetists, local blocks remained the main anaesthetic option for ocular procedures. This appears to be in keeping with global trends. However, the findings in this study indicate that the paediatric patients and non-elective procedures were the main indications for general anaesthesia.

Anaesthesia for paediatric ophthalmic procedures deserves special mention. Ophthalmic anaesthesia for children requires quick onset, safety on repeated use, minimal change 
in intraocular pressure, complete access to the eye, unusual position of the head for fundal examination, and rapid recovery, especially in the outpatient setting. ${ }^{7}$ General anaesthesia meets these conditions and has been suggested as the preferred technique for paediatric cataract surgery. ${ }^{8}$ In a study in Benin, about $80 \%$ of the ophthalmic surgical procedures in children were performed under general anaesthesia. ${ }^{9}$ Nevertheless, several other techniques have been evaluated for ocular procedures in children to meet the challenges of the dearth of anaesthetic personnel or equipment, general anaesthesia related complications, or for better management of postoperative pain. Fan and colleagues ${ }^{10}$ demonstrated the use of peribulbar block in children aged 7-15 years. The authors concluded that peribulbar block is an alternative anaesthetic technique in carefully selected paediatric patients who undergo cataract surgery in places where anaesthetic expertise or facilities for general anaesthesia are lacking. Similarly, Madan and coworkers ${ }^{11}$ demonstrated the safety and feasibility of TIVA in children presenting for repeated diagnostic ophthalmic procedures. In addition, the use of peribulbar block as an adjunct to general anaesthesia reduced postoperative pain and decreased the incidence of postoperative nausea and vomiting (PONV) and oculocardiac reflex (OCR). Besides these advances, some of these techniques may not be appropriate in a wide range of paediatric population.

Emergency or non-elective ocular procedure was another major reason for general anaesthesia in this study. Ocular trauma is one of the leading indications for emergency ophthalmic anaesthesia. When it is an open globe injury, maintaining ocular akinesia and avoidance of increases in intraocular pressure become essential requirements for anaesthesia. Thus, general anaesthesia is considered the technique of choice for significant ocular trauma albeit an emergency ophthalmic procedure. Topical anaesthesia with sedation was evaluated for the repair of open globe injury so as to avoid the morbidity associated with general anaesthesia. ${ }^{12}$ The results of the aforementioned study ${ }^{12}$ must be interpreted with caution. Expertise with topical anaesthesia is not widespread..$^{13}$ In addition, the limited number of cases, the method of selection and lack of comparison with other methods of anaesthesia argue against the perceived benefits of topical anaesthesia for open globe injury as shown by the authors.

In order to maintain quality and safety in ophthalmic anaesthesia, the personnel requirement for ophthalmic anaesthesia should not be different from that of other surgical specialties. Anaesthetists were only involved in the administration of general anaesthesia for ophthalmic procedures. At present in our centre, anaesthetists are not involved in the administration of local anaesthesia for ocular procedures. The non-availability of sufficient number of anaesthetists may be a factor. However, the United Kingdom Colleges of Anaesthetists and Ophthalmologists have jointly produced guidelines for the perioperative management of patients undergoing ocular surgery. ${ }^{14}$ The document emphasizes the training and expectations from the anaesthetists as well as the ophthalmologists. It is important that similar guidelines should be developed in the sub-region with the aim of streamlining the training of anaesthetists in local block for ophthalmic procedures. In addition, the lack of equipment for general anaesthesia, prompting the use of intravenous ketamine for paediatric eye surgery, ${ }^{15}$ underscores the difficulties with anaesthetic equipment and personnel in developing countries.

This study is not without limitations. It did not record the rate of failed blocks and consequent conversion to general anaesthesia. This would have provided information on procedures that are not quite amenable to local anaesthesia in the sub-region. Second, the associated side effects of the various techniques of anaesthesia were not evaluated. This would have been difficult on account of the retrospective nature of this study. These limitations notwithstanding, our observation of the relationship between age and circumstances of surgery and the choice of anaesthetic techniques would facilitate efficient scheduling and use of operating room time.

\section{CONCLUSION}

This retrospective study evaluated the pattern and determinants of anaesthesia for ophthalmic procedures in a teaching hospital. The ocular procedures were performed in inpatient and outpatient settings. Local anaesthesia was the main anaesthetic technique for the procedures. General anaesthesia was preferentially administered for procedures in children and in emergency surgery. It is suggested that these circumstances should be considered in scheduling ophthalmic procedures.

\section{REFERENCES}

1. Venkatesan VG, Smith A. What's new in ophthalmic anaesthesia? Curr Opin Anaesthesiol 2002; 15: 615-20.

2. Novak KD, Koch DD. Topical anaesthesia for phacoemulsification: Initial 20 case series with one month follow-up. J Cataract Refract Surg 1995; 21: 672-5.

3. Katz J, Feldman MA, Bass EB, Lubomski LH, Teilsch JM, Petty BG, Fleisher LA, Schein OD. Adverse intraoperative medical events and their association with anaesthesia management strategies in cataract surgery. Ophthalmology 2001; 108: 1721-6.

4. Kubitz J, Epple J, Bach A, Motsch J, Martin E, Schmidt H. Psychomotor recovery in very old patients after total intravenous or balanced anaesthesia for cataract surgery. $\mathrm{Br} J$ Anaesth 2001; 86: 203-8). 
CO Imarengiaye, SA Adamu, T Isesele and SO Tudjegbe

5. Deb K, Subramaniam R, Dehran M, Tandon R, Shende D. Safety and efficacy of peribulbar block as adjunct to general anaesthesia for paediatric ophthalmic surgery. Paediatr Anaesth 2001; 11: 161-7.

6. Norregaard JC, Schein OD, Bellan L et al. International variation in anaesthesia care during cataract surgery. Results from the International Cataract Surgery Outcomes. Arch Ophthalmol 1997; 115: 1304-8.

7. Hannallah RS, Ebstein BS. Outpatient anaesthesia. In: Gregory GA, ed. Pediatric Anaesthesia, $3^{\text {rd }}$ edn. New York. Churchill Livingstone, 1994: 779.

8. Wilson ME, Pandey SK, Thakur J. Paediatric cataract blindness in the developing world: surgical techniques and intraocular lenses in the new millennium. Br J Ophthalmol 2003; 87: 14-19).

9. Osahon AI, Dawodu OA. Ophthalmic surgical procedures in children at the University of Benin Teaching Hospital, Benin City. Journal of Medicine and Biomedical Research 2002; 1: 7-11.

10. Fan DSP, Tang EWH, Rao ZX, Lam DSC. The use of peribulbar anaesthesia in paediatric cataract surgery (age 7-15years) in a mobile eye camp in China. Acta Ophthalmol Scand 2006; 84: 3847.

11. Madan R, Kapoor I, Balchander S, Kathirvel S, Kaul HL. Propofol as sole agent for paediatric day care diagnostic ophthalmic procedures: comparison with halothane anaesthesia. Paediatr Anaesth 2001; 11: 671-7.

12. Boscia F, Tegola MG, Columbo G, Alessio G, Sborgia C. Combined topical anaesthesia and sedation for open globe injuries in selected patients. Ophthalmology 2003; 110: 1555-9.

13. Bethke W. Cataract surgeons move on. Rev Ophthalmol 1996; 3: 60-4.

14. Local anaesthesia for intraocular surgery, London: Royal College of Anaesthetists and Royal College of Ophthalmologists, 2001 www.rcoa.ac.uk

15. Nwosu SNN. Paediatric eye surgery in Onitsha, Nigeria. Nig J Surg 1995; 2: 43-47. 